\title{
Exploring Land Cover Classification Accuracy of Landsat 8 Image Using Spectral Index Layer Stacking in Hilly Region of South Korea
}

\author{
Jae Kang Lee, ${ }^{1}$ Tri Dev Acharya, ${ }^{2}$ and Dong Ha Lee ${ }^{2 *}$ \\ ${ }^{1}$ LX Korea Cadastral Surveying Corporation, \\ 120, Giji-ro, Wansan-gu, Jeonju, Jeollabuk 54870, Republic of Korea \\ ${ }^{2}$ Department of Civil Engineering, Kangwon National University, \\ 1 Kangwondaehak-gil, Chuncheon, Gangwon 24341, Republic of Korea
}

(Received February 14, 2018; accepted May 1, 2018)

Keywords: land cover, layer stacking, Landsat, spectral index, supervised classification

Remote sensing has been providing solutions in a variety of sectors as a result of the recent growth in technology and available data. Land cover mapping is the most widely used application of remote sensing, yet it has always been a challenging task owing to various complexities. Consequently, constant studies have been conducted for the improvement of land cover classification accuracy using new datasets or algorithms in various cases. Because of free availability and high temporal coverage, Landsat data series are frequently chosen in studies of land cover mapping. In addition, various spectral indices (SIs) have been developed to separate a single feature very efficiently. Some of the derived SIs were stacked with an original multispectral image in some studies, in expectation of better classification results. In this study, we investigate whether the stacking of layers with different SIs derived from reflectance data could improve the land cover classification of Landsat OLI image in a hilly region of South Korea. A decision tree was used for the selection of SIs that aid classification. For that, five supervised classifiers, namely, Mahalanobis distance (Mahd), maximum likelihood (ML), minimum distance to means (MinD), parallelepiped (PP), and support vector machine (SVM), in three cases of a study area were applied with the same training and validation data to compare the accuracy of the results for original and two derived composites. Out of 45 land cover cases, 28 cases showed improvements by layer stacking indices. PP showed improvement in all cases but at the cost of unclassified pixels. MahD and SVM showed improvement in most cases with higher classification accuracy. ML was unable to classify the composite with all derived bands. In conclusion, layer stacking of the derived bands, even two normalized difference vegetation index and normalized difference water index, was able to improve the overall accuracy. Improving the accuracy of land cover maps would provide accurate information and is beneficial to authorities for a better understanding and analysis of the environment.

*Corresponding author: e-mail: geodesy@kangwon.ac.kr https://doi.org/10.18494/SAM.2018.1934 


\section{Introduction}

Remote sensing is a rapidly growing space technology that has been providing significant solutions in the areas of natural resource management and environmental assessments. With the availability of remotely sensed data from different sensors of various platforms with a wide range of spatiotemporal, radiometric, and spectral resolutions, the technology has been applied to a variety of sectors such as agriculture, forestry, geology, hydrology, land use, and land cover. ${ }^{(1)}$

In the past two decades or so, land cover mapping has been the most popular application of remote sensing research. ${ }^{(2)}$ "Land cover" is a separate yet interchangeable terminology that refers to the physical characteristics of the earth's surface, together with the distribution of vegetation, water, desert, ice, and other physical features of land, including those of anthropogenic origins, e.g., settlements, industries, and mines. ${ }^{(3)}$ Accurate and up-to-date land cover maps provide better visualization of the environment and aid in planning, modeling, and decision-making processes in natural resource management. The production of frequent and more accurate land cover maps has always been a challenging task due to terrain, landscape complexity, land cover pattern, selection of suitable bands (original or derived), image processing, and classification approaches, for example. ${ }^{(4,5)}$ Examples of the most common classification algorithms include the k-means, iterative self-organizing data analysis technique, Mahalanobis distance (MahD), maximum likelihood (ML), parallelepiped (PP), and minimum distance to means (MinD), while advanced classification algorithms include artificial neural networks (ANN), decision trees (DT), support vector machine (SVM), and object-based image analysis (OAA). ${ }^{(6,7)}$ A review of different classification approaches has been given by $\mathrm{Lu}$ and Weng. ${ }^{(4)}$ Gómez et al. ${ }^{(8)}$ have provided a comprehensive review of optical remotely sensed time series data for land cover classification, along with studies, strengths, and weaknesses of these methods.

In the past, several contributions have been made toward the improvement of land cover classification accuracy from remotely sensed images through the use of indices derived from the same or different data sets, ancillary data, and combined data from two or more sensors. ${ }^{(9-12)}$ Spectral indices (SIs) are derivatives from satellite data that have been widely used to estimate environmental variables of interest such as water, soil, and built-ups. ${ }^{(13-15)}$ However, these SIs are effective only in separating one type of feature. Hence, the stacking of layers with different SIs in accordance with the specific land cover in a study area can aid in the improvement of classification accuracy.

Because of free-of-charge availability, longer history, and higher archiving frequency, the Landsat series has been providing earth imagery regularly since the 1970s. The images are frequently used for land cover classification on regional, continental, and global scales. ${ }^{(16-20)}$ In addition, technical advances in the past decade have yielded precise spatial and calibrated radiometric alignment of Landsat images. The most recent operational land imager (OLI) onboard Landsat 8 launched on 11 February $2013^{(21)}$ has several improvements over its predecessors, namely, the thematic mapper (TM; Landsat 4 and 5) and the enhanced thematic mapper (ETM+; Landsat 7). The main changes include an increased number of spectral bands, a higher radiometric resolution (12 bits), and an improved signal-to-noise ratio resulting 
from the use of a push-broom sensor. Because of the various sensor characteristics, there are differences in SIs derived from multiple sensors for the same target. ${ }^{(22)}$ The differences in spectral reflectance and normalized difference vegetation index (NDVI) values have also been observed in OLI data compared with ETM+. ${ }^{(23-25)}$ Hence, the SIs derived from improved reflectance may enable better characterization and mapping of environmental variables, states, and conditions.

Layer stacking has been frequently used in the classification of single or multiple land cover features from satellite images. Zhou et al. ${ }^{(26)}$ used NDVI, enhanced vegetation index (EVI), and land surface water index (LSWI) for each image used to demonstrate the potential of the phenology-based rice paddy mapping algorithm, obtained by integrating MODIS and Landsat 8 OLI images, to map paddy rice fields in complex landscapes comprising rice paddies and natural wetland in a temperate region. Rawat and Kumar ${ }^{(27)}$ applied NDVI, normalized difference water index (NDWI), and normalized difference built-up index (NDBI) derived from Landsat TM images to monitor the change in land cover by the supervised ML method. Ko et $a l .{ }^{(28)}$ used top-of-atmosphere (TOA) reflectance and water indices [NDWI and two modified NDWI (MNDWI)] derived from the Landsat 8 OLI sensor and its corresponding random forest classifiers for robust water-body classification. Otukei and Blaschke ${ }^{(11)}$ used the first three principal components (PCs), the first three tasselled cap (TC)-transformed bands, NDVI, and the texture band based on spectral variance with a $3 \times 3$ moving window in Landsat TM and ETM+ images in DT, SVM, and ML to assess land cover change in the Pallisa District, Eastern Uganda. However, the use of these derived bands were only assumptions for better classification without comparison with raw data. Recent multispectral image and classifiers provide higher classifications, yet even a slight improvement in the result would be highly beneficial in mapping communities.

The objective of this study is to investigate the hypothesis that the stacking of layers with different SIs derived from TOA reflectance data could improve the land cover classification of Landsat OLI image in hilly regions of South Korea. For this objective, a suitable study area was selected. Obtained data were converted to TOA reflectance and various SIs were derived and then stacked into one. Training and validation data from high-resolution images available in Google Earth Pro (GEP) acquired on the same date were used for the classification and accuracy assessment of the results. Finally, the five most common classifiers, namely, MahD, ML, MinD, PP, and SVM, were applied on the original and two stacked composites to compare the accuracy of results. The overall workflow of the study is shown in Fig. 1.

\section{Materials and Methods}

\subsection{Study area}

A total area of 2944 sq. km in the central south region of South Korea was selected for study. Most of the area lies in Jeollabuk province and a few adjacent portions of adjacent provinces. The area is geographically bounded by $35^{\circ} 14^{\prime} 8.43^{\prime \prime} \mathrm{N}$ to $36^{\circ} 1^{\prime} 40.32^{\prime \prime} \mathrm{N}$ and $127^{\circ} 21^{\prime} 9.64^{\prime \prime} \mathrm{E}$ to $127^{\circ} 42^{\prime} 36.69^{\prime \prime} \mathrm{E}$. The elevation in the study area varies from 33 to $1799 \mathrm{~m}$ above sea level. The 


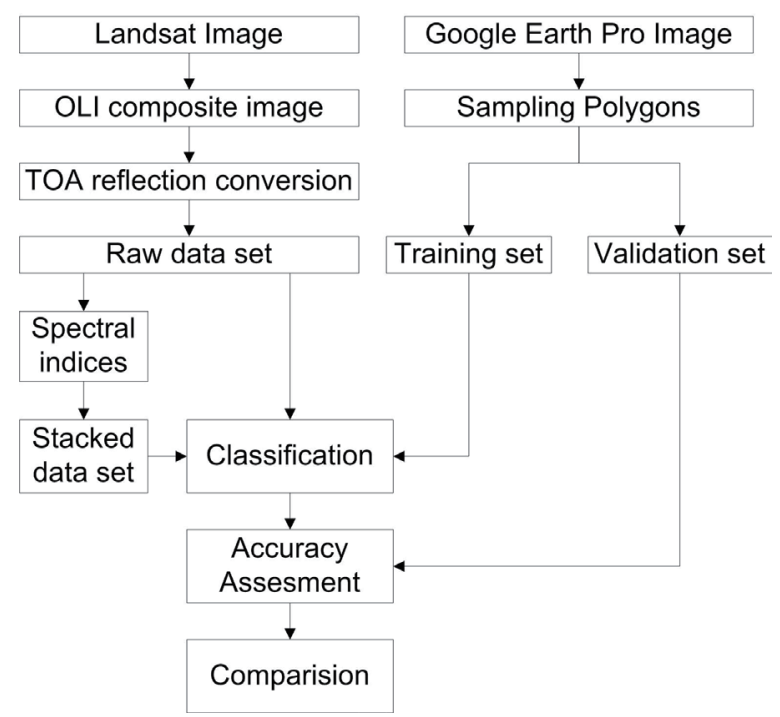

Fig. 1. Overall work flowchart adopted in this study.

area is mostly hilly with forest and agricultural land. In addition, few large water reservoirs and dense built-up areas also lie in the area. The area was selected for its typical land cover that is representative of hilly regions of South Korea.

To better understand the role of SIs in the classification process, the study area is divided into two halves (Fig. 2). The complete classification process was carried out on three study areas, i.e., upper (1513 sq. km), lower (1431 sq. km), and combined.

\subsection{Data and preprocessing}

The data used in the study was of the Landsat 8 image obtained from the United States Geological Survey (USGS) EarthExplorer portal and the high-resolution georeferenced image available in GEP. The Landsat 8 data was of the geometrically corrected level-1T image, acquired on May 26, 2015 in the worldwide reference system path 115 and row 35 and pregeoreferenced to the UTM zone 52 North projection in the WGS84 datum. The spectral wavelength ranges and the spatial resolution bands of Landsat 8 , along with the applications, are presented in Table 1.

In Environment for Visualizing Images (ENVI) version 5.1 image processing software, a Landsat calibration tool was used to convert the digital numbers (DNs) of the OLI bands into TOA reflectance. The required coefficients and values, including the Data Acquisition Date and Sun Elevation, were obtained from the Landsat MTL header file. After that, a subset image was extracted from the scene as the study area. The image quality of the study area was good and cloud free.

The high-resolution georeferenced image available in GEP was used as training data for image classification and training data for overall accuracy assessment. The images available in GEP were acquired on the same day as the Landsat 8 image, i.e., May 26, 2015. Thus, the two same-date images ensure identical land cover conditions. 


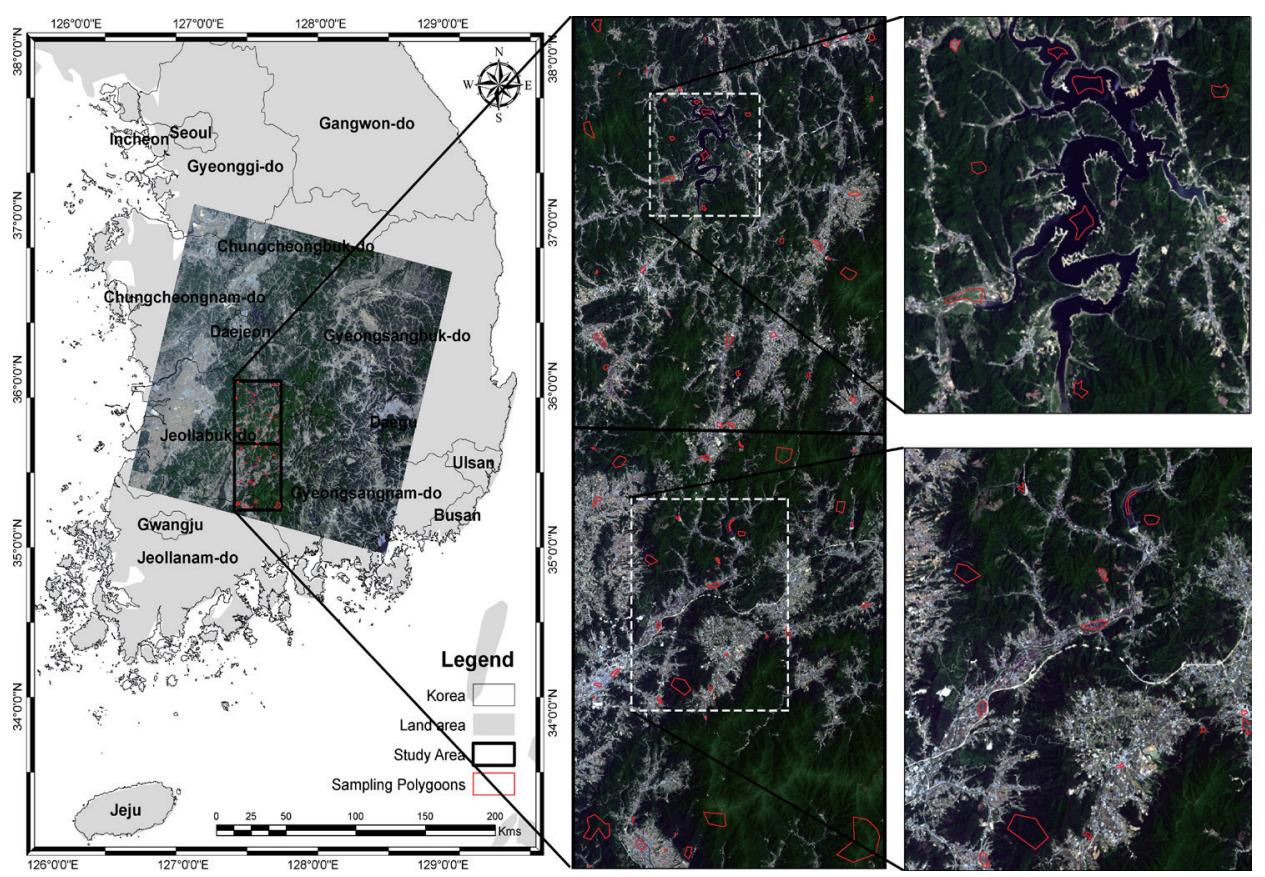

Fig. 2. (Color online) Location map of the study area in Korea, with sampling polygons on Landsat 8 scene natural color composite image taken on May 26, 2015.

Table 1

Spectral bands of Landsat 8 OLI.

\begin{tabular}{|c|c|c|c|c|}
\hline Band No. & Band name & $\begin{array}{l}\text { Spectral ranges } \\
(\mu \mathrm{m})\end{array}$ & $\begin{array}{l}\text { Spatial resolution } \\
(\mathrm{m})\end{array}$ & Applications \\
\hline 1 & Deep blue & $0.43-0.45$ & 30 & Coastal and aerosol studies \\
\hline 2 & Blue & $0.45-0.51$ & 30 & $\begin{array}{c}\text { Bathymetric mapping, distinguishing } \\
\text { soil from vegetation and deciduous } \\
\text { from coniferous vegetation }\end{array}$ \\
\hline 3 & Green & $0.53-0.59$ & 30 & Assessment of vegetation vigor \\
\hline 4 & Red & $0.64-0.67$ & 30 & $\begin{array}{l}\text { Chlorophyll absorption } \\
\text { for vegetation discrimination }\end{array}$ \\
\hline 5 & Near infrared (NIR) & $0.85-0.88$ & 30 & $\begin{array}{l}\text { Emphasizes biomass content and } \\
\text { waterbodies/shorelines }\end{array}$ \\
\hline 6 & $\begin{array}{l}\text { Short-wave infrared } 1 \\
\text { (SWIR_1) }\end{array}$ & $1.57-1.65$ & 30 & $\begin{array}{l}\text { Discriminates moisture content of soil } \\
\text { and vegetation; thin cloud penetration }\end{array}$ \\
\hline 7 & $\begin{array}{l}\text { Short-wave infrared } 2 \\
\text { (SWIR_2) }\end{array}$ & $2.11-2.29$ & 30 & $\begin{array}{l}\text { Improved discrimination of moisture } \\
\text { content of soil and vegetation; } \\
\text { thin cloud penetration }\end{array}$ \\
\hline 8 & Panchromatic & $0.50-0.68$ & 15 & $\begin{array}{l}\text { Sharper image definition } \\
\text { for visual interpretation }\end{array}$ \\
\hline 9 & Cirrus & $1.36-1.38$ & 30 & $\begin{array}{l}\text { Improved detection of cirrus cloud } \\
\text { contamination }\end{array}$ \\
\hline 10 & $\begin{array}{l}\text { Thermal infrared } 1 \\
\text { (TIR_1) }\end{array}$ & $10.60-11.19$ & $100^{*}$ & $\begin{array}{l}\text { Thermal mapping and estimated soil } \\
\text { moisture }\end{array}$ \\
\hline 11 & $\begin{array}{l}\text { Thermal infrared } 2 \\
\text { (TIR_2) }\end{array}$ & $11.50-12.51$ & $100^{*}$ & $\begin{array}{l}\text { Improved thermal mapping and } \\
\text { estimated soil moisture }\end{array}$ \\
\hline BQA & Quality assessment & & & $\begin{array}{l}\text { Quality assessments for every pixel } \\
\text { in the scene }\end{array}$ \\
\hline
\end{tabular}

${ }^{*}$ TIRS bands are acquired at $100 \mathrm{~m}$ resolution, but are resampled to $30 \mathrm{~m}$ in the delivered data product. ${ }^{(29,30)}$ 


\subsection{Spectral index and layer stacking}

SIs have been successfully used in several classification studies. To achieve better classification results, 13 SIs resulting in 16 derivative layers from TOA reflectance were also created. The selection of the indices was based on the condition of the land cover class present in the study area. Table 2 shows the spectral reference, formulae, and reference of the TOA reflectance-based SIs of Landsat 8 OLI bands applied in the study area.

As the season of the study area is early summer, most of the forest area is green, and different vegetation indices (VIs) were calculated to enhance vegetation spectral distribution. VIs have been used in vegetation studies, especially to assess the health of vegetation, which could provide valuation information in classification approaches. VIs used in the studies are shown in Table 2, along with the formulae and references. The use of multiple VIs could also help in identifying the VIs with higher information gain during classification.

For water detection, LSWI, NDWI, and two MNDWIs were used. NDWI is designed to maximize the reflectance of a water body by using a green wavelength, minimize the low reflectance in NIR, and take advantage of the high reflectance in NIR of vegetable and soil features. ${ }^{(42)}$ The modified version of NDWI, MNDWI, was developed to enhance open water features by efficiently suppressing and even removing built-up, land noise as well as vegetation and soil noise. Two bands for each LSWI and MNDWI were derived on the basis of two SWIR bands.

Table 2

TOA reflectance-based SIs of Landsat 8 OLI bands applied in the study area.

\begin{tabular}{|c|c|c|c|}
\hline SI No. & Spectral index & Formula & Reference \\
\hline 1 & $\begin{array}{l}\text { Enhanced vegetation index } \\
\text { (three bands) (EVI) }\end{array}$ & $2.5 \times(\mathrm{NIR}-\mathrm{Red}) /(\mathrm{NIR}+6 \times$ Red $-7.5 \times$ Blue +1$)$ & (31) \\
\hline 2 & $\begin{array}{l}\text { Enhanced vegetation index } \\
\text { (two bands) (EVI2) }\end{array}$ & $2.5 \times(\mathrm{NIR}-\mathrm{Red}) /(\mathrm{NIR}+2.4 \times \operatorname{Red}+1)$ & (32) \\
\hline 3 & Land surface water index (LSWI) & $(\mathrm{NIR}-\mathrm{SWIR}) /(\mathrm{NIR}+\mathrm{SWIR})$ & (33) \\
\hline 4 & $\begin{array}{l}\text { Modified normalized difference water } \\
\text { index (MNDWI) }\end{array}$ & $($ Green $-\mathrm{SWIR}) /($ Green + SWIR $)$ & (34) \\
\hline 5 & Modified simple ratio (SR) & $(\mathrm{NIR} / \mathrm{Red})-1) /(\sqrt{ }(\mathrm{NIR} / \mathrm{Red})+1)$ & (35) \\
\hline 6 & $\begin{array}{l}\text { Normalized difference built-up index } \\
\text { (NDBI) }\end{array}$ & $(\mathrm{SWIR}-\mathrm{NIR}) /(\mathrm{SWIR}+\mathrm{NIR})$ & $(36)$ \\
\hline 7 & $\begin{array}{l}\text { Normalized difference vegetation index } \\
\text { (NDVI) }\end{array}$ & $(\mathrm{NIR}-\mathrm{Red}) /(\mathrm{NIR}+\mathrm{Red})$ & $(37)$ \\
\hline 8 & $\begin{array}{l}\text { Normalized difference water index } \\
\qquad(\mathrm{NDWI})\end{array}$ & $($ Green $-\mathrm{NIR}) /($ Green + NIR $)$ & (38) \\
\hline 9 & Soil-adjusted vegetation index (SAVI) & $1.5 \times(\mathrm{NIR}-\mathrm{Red}) /(\mathrm{NIR}+\mathrm{Red}+0.5)$ & (39) \\
\hline 10 & Simple ratio (SR) & NIR/Red & $(40)$ \\
\hline 11 & $\begin{array}{l}\text { Tasselled cap transformation brightness } \\
\text { (TCT_B) }\end{array}$ & $\begin{array}{c}0.3029 \times \text { Blue }+0.2786 \times \text { Green }+0.4733 \times \text { Red }+ \\
0.5599 \times \text { NIR }+0.508 \times \text { SWIR_1 }+0.1872 \times \text { SWIR_2 }\end{array}$ & (41) \\
\hline 12 & $\begin{array}{l}\text { Tasselled cap transformation greeness } \\
\text { (TCT_G) }\end{array}$ & $\begin{array}{c}-0.2941 \times \text { Blue }-0.243 \times \text { Green }-0.5424 \times \text { Red }+ \\
0.7276 \times \text { NIR }+0.0713 \times \text { SWIR_1 }-0.1608 \times \text { SWIR_2 }\end{array}$ & (41) \\
\hline 13 & $\begin{array}{l}\text { Tasselled cap transformation wetness } \\
\text { (TCT_W) }\end{array}$ & $\begin{array}{c}0.1511 \times \text { Blue }+0.1973 \times \text { Green }+0.3283 \times \text { Red }+ \\
0.3407 \times \text { NIR }-0.7117 \times \text { SWIR_ } 1-0.4559 \times \text { SWIR_ } 2\end{array}$ & (41) \\
\hline
\end{tabular}


NDBI was used for the detection of built-up areas. It highlights urban areas where there is typically a higher reflectance in the SWIR region than in the NIR region. Like the MNDWI, two NDBIs were derived as per two SWIR bands in OLI data.

Similarly, the three tasselled cap transformed (TCT) bands were chosen since they represent the "greenness", "brightness", and "wetness" axes, and therefore provide a measure of the presence or absence of vegetation as well as of areas with high moisture content. The coefficients to derive TCT bands for OLI were taken from the result obtained by Baig et al. ${ }^{(41)}$

As suitable bands, whether original or derived ones, play an important role in improving the classification, ${ }^{(4)}$ DT could yield the minimum bands with high information gain and the decision threshold for classification in the composite dataset. In this study, the J48 model available in the data mining software Waikato Environment for Knowledge Analysis (WEKA) ${ }^{(43)}$ was used. Derived bands with only information gain for the classifications were selected to form a new final composite through layer stacking.

\subsection{Sampling training and validation dataset}

Training and validation data for the associated classes were delineated on the basis of an analyst's prior knowledge of the study area. First, polygonal regions of interest (ROI) were selected on the image in GEP. For all four ROIs, $70 \%$ of the pixels were selected for training and the remaining $30 \%$ were selected for validation, as shown in Table 3 .

\subsection{Classification and accuracy assessment}

A total of five supervised classifiers were selected for the classification of the multispectral image without and with layer-stacked SIs (newly derived after DT), namely, MahD, ML, MinD, $\mathrm{PP}$, and SVM. The ENVI was used in all classifications. All the classifiers are well known and widely used for land cover classification and are available in ENVI.

MahD classification is a direction-sensitive distance classification in which statistics are used for each class and all class covariances are assumed to be equal; therefore, it is a faster method. ${ }^{(7)}$ All pixels are classified to the closest ROI class unless a distance threshold is specified, in which case, some pixels may be unclassified if they do not meet the threshold. ${ }^{(44)}$

The MinD classfier uses the mean vectors of each end member and calculates the Euclidean distance from each unknown pixel to the mean vector for each class. All pixels are classified to the nearest class unless a standard deviation or distance threshold is specified, in which case, some pixels may be unclassified if they do not meet the selected criteria. ${ }^{(44)}$

Table 3

Number of ROI polygons in the study.

\begin{tabular}{lccccccc}
\hline \multirow{2}{*}{ Study area } & \multicolumn{3}{c}{ Land cover polygons } & \multicolumn{3}{c}{ Sampling pixels } \\
\cline { 2 - 8 } & Water & Forest & Built-up & Land & Training & Validation & Total \\
\hline Upper & 12 & 10 & 6 & 10 & 7400 & 3172 & 10572 \\
Lower & 12 & 10 & 6 & 10 & 23032 & 9870 & 32902 \\
Combined & 24 & 20 & 12 & 20 & 30432 & 13042 & 43474 \\
\hline
\end{tabular}


ML is one of the most commonly used parametric classifiers for supervised classification because of its simplicity and robustness. ${ }^{(7)}$ It assumes that the statistics for each class in each band are normally distributed and calculates the probability that a pixel or object belongs to each class and then assigns the pixel or object to the class with the highest probability. If the highest probability is smaller than a specified threshold, the pixel remains unclassified. ${ }^{(4)}$

PP classification uses a simple decision rule to classify a multispectral image. The decision boundaries form an n-dimensional parallelepiped classification in the image data space. The dimensions of the parallelepiped classification are defined on the basis of a standard deviation threshold from the mean of each selected class. If a pixel value lies between the low and high thresholds for all $\mathrm{n}$ bands being classified, it is assigned to that class. If the pixel value falls into multiple classes, ENVI assigns the pixel to the first matched class. Areas that do not fall within any of the parallelepiped classes are designated as unclassified. ${ }^{(4)}$

The SVM is also a non-parametric learning algorithm used for classification and regression. The success of the SVM depends on how well the process is trained. The SVM often yields good classification results from complex and noisy data, and thus, is often used as the reference state-of-the-art method for the comparison of various object identification and classification results in different cases. ${ }^{(11,45)}$

The study area was classified into four land cover classes: water, forest, built-up area, and land (Table 4). These classes represent the most dominant and important types of land cover in the area. The selection of only four classes was for the sake of ease and to decrease the possibility of misclassification.

Finally, we used the producer's accuracy (PA), user's accuracy (UA), and overall accuracy (OA), and Kappa statistics, which were calculated from error matrix, to compare the performance of classified maps. A score table was also prepared to visualize the improvement in classification of each classifier and study area.

\section{Results and Discussion}

First, all the pixels from the sampling polygons were transformed into table format along with all the pixel values from 23 individual layers. Three different tables were formed as per upper, lower, and combined study area. Each table was processed in WEKA using the J48 model to form the DT. The suitable SIs for layer stacking were selected on the basis of the sum of the number of repetitions in the DT. Figure 3 show the example of DT for the combined study area.

Table 4

Land cover classes in this study.

\begin{tabular}{lcc}
\hline Class No. & Class Name & Description \\
\hline 1 & Water & River, ponds, lakes, and reservoirs \\
2 & Forest & Mixed grasslands and forests \\
3 & Built-up area & Residential, commercial, industrial, roads, and mixed urban areas \\
4 & Land & Crop fields, fallow lands, exposed soil, and barren areas \\
\hline
\end{tabular}




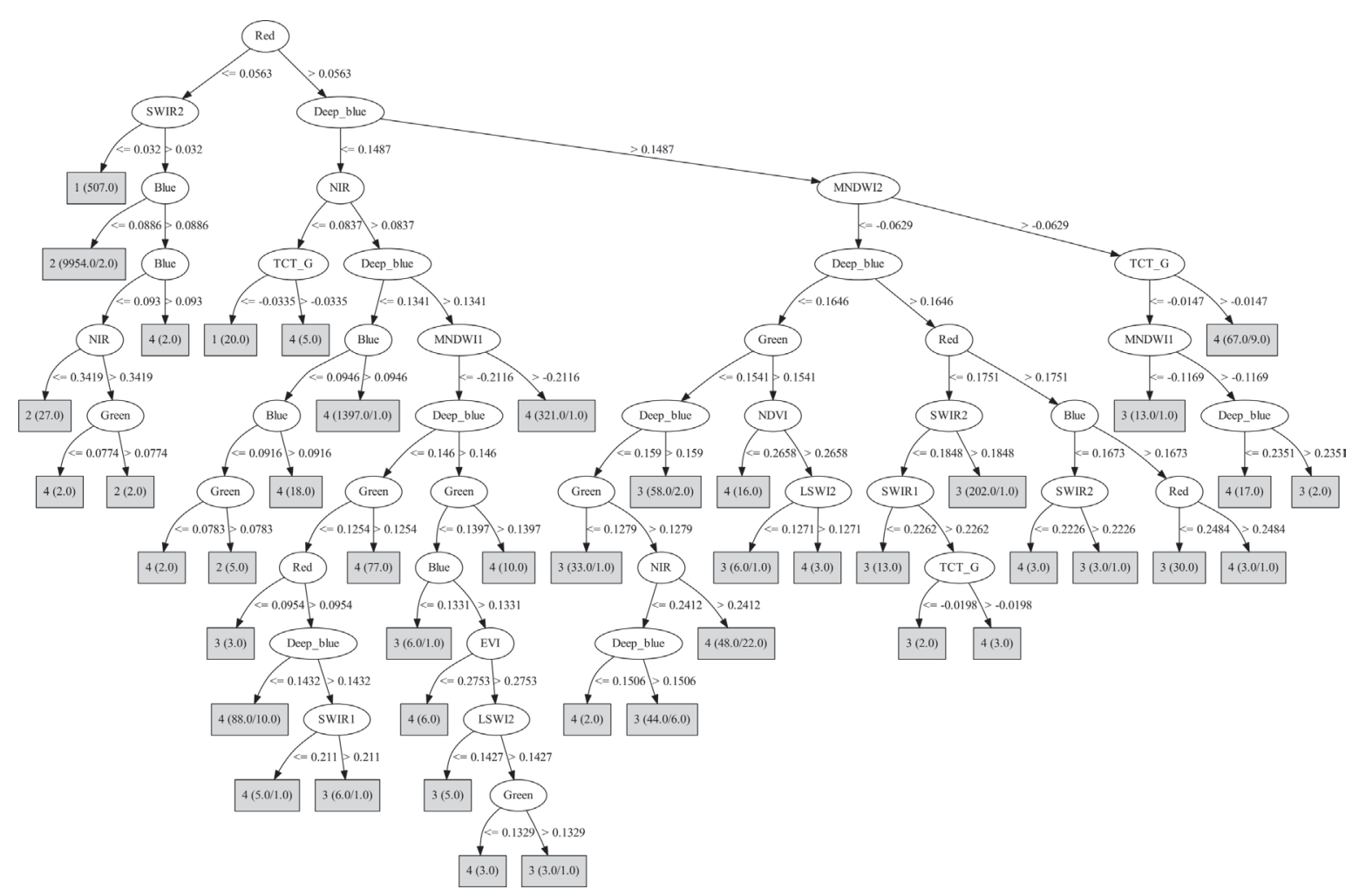

Fig. 3. Example of DT for the combined study area using all 23 bands based on sampled polygon pixels. The bands used in all the three cases of DT were only used for final Comp 18 .

In the DT for all three cases, five derivative bands (MSR, NDBI1, NDBI2, SAVI, and SR) were rejected and not even used once, and TCT Brightness and Greenness were used only a few times. Consequently, the deep blue, NDWI, and red bands were most repeated in the DTs. With the selected SIs, these were stacked with the original multispectral image in two ways: 7 original bands with two SIs (NDVI and NDWI) so that the new image comprises 9 bands (Comp9), and 7 original bands with 11 SIs so that the new image has 18 bands (Comp 18$)$.

For the original ( $\mathrm{Comp}_{7}$ ), and two new stacked composite (Comp 9 and Comp 18 ) images, each of the three areas (i.e., upper, lower, and combined) were classified on the basis of the five classification models trained using the 70\%-pixel samples. A total of 45 classified land cover maps were derived. Figures 4-6 show examples of the classification results of upper, lower, and combined study areas using MahD, PP, and SVM classifiers, respectively, for all three composites.

The remaining $30 \%$ of the pixels from the sampled polygons were used in the accuracy assessments. The results of the accuracy assessment are shown in Tables 5-7 where PA, UA, and OA for each class and the Kappa coefficient for each classifier are shown. The classification accuracies of MahD, ML, and SVM seem to be high, whereas MinD and PP show poor classification accuracy. To our surprise, the ML was unable to classify the Comp 18 composite image and PP was unable to classify some pixels in all study areas. Similarly, the PAs of water and forest seem to be very high, even $100 \%$ in some cases, whereas built-up 


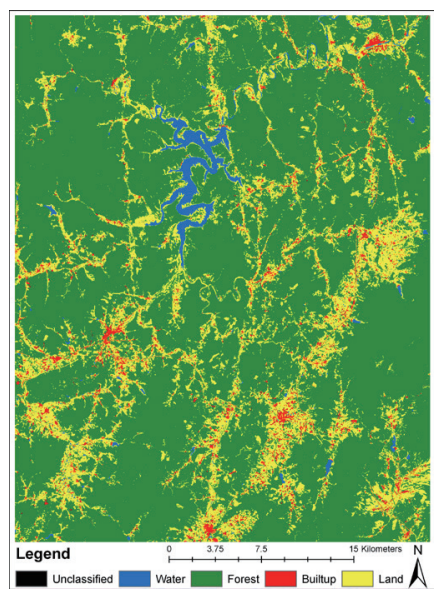

(a)

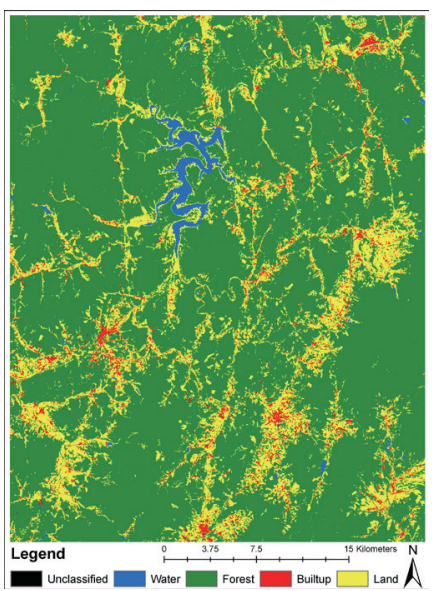

(b)

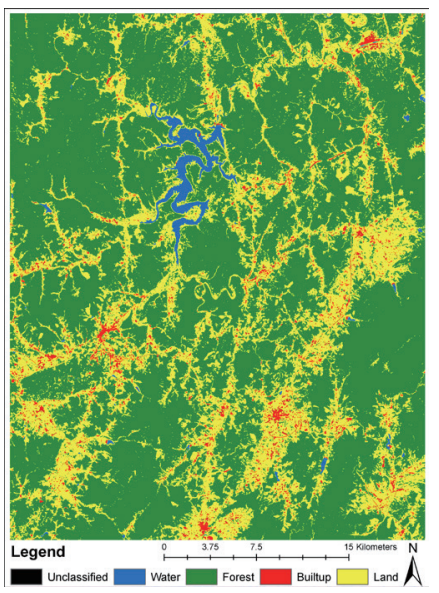

(c)

Fig. 4. (Color online) Results of land cover in upper study area using MahD classification for composite data: (a) original OLI (Comp7), (b) OLI bands with NDVI and NDWI (Comp9), and (c) OLI bands with all SIs (Comp 18 ).

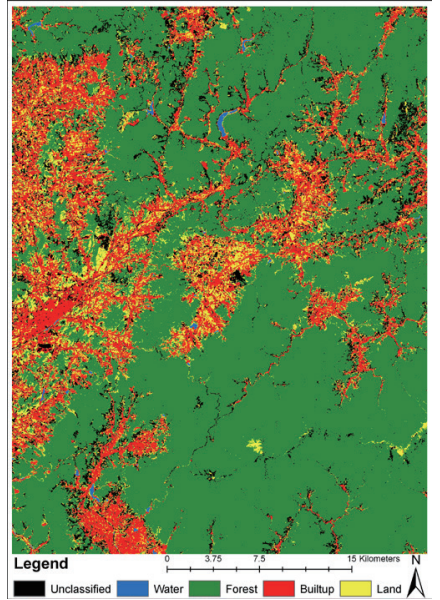

(a)

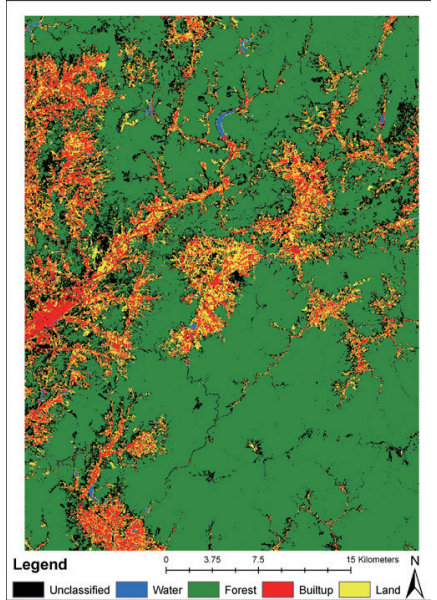

(b)

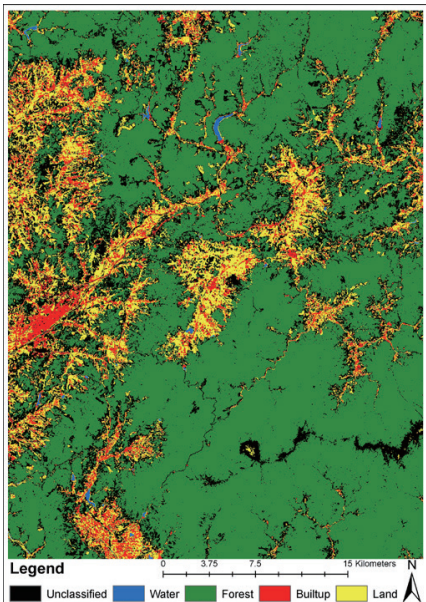

(c)

Fig. 5. (Color online) Results of land cover in lower study area using PP classification for composite data: (a) original OLI (Comp 7 ), (b) OLI bands with NDVI and NDWI (Comp9), and (c) OLI bands with all SIs (Comp 18 ).

area and land showed poor results and the classification results were often interchanged with each other. In particular, MinD and PP classified land as built-up in all cases. The common misclassifications in the results are shown in Fig. 7.

From the accuracy assessment tables, a score table is prepared, as shown in Table 8, which shows whether there is improvement in classification or not. An improvement in the OA is scored as 1 whereas a decrease in accuracy is scored as 0 . As seen in the table, there is improvement in the overall accuracy for all classifiers except ML. Out of 45 cases, $62 \%$ showed improvement, and if ML is removed from the evaluation, $77 \%$ of the cases were improved. The most improved classification is PP but at a cost of unclassified pixels. MahD showed only improvement with the Comp 18 composite, but not the Comp 9 composite in the upper and lower 


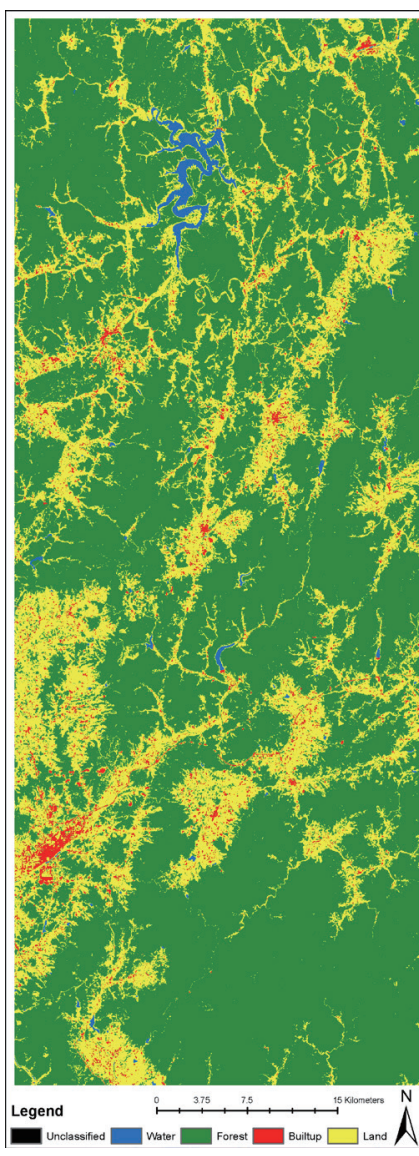

(a)

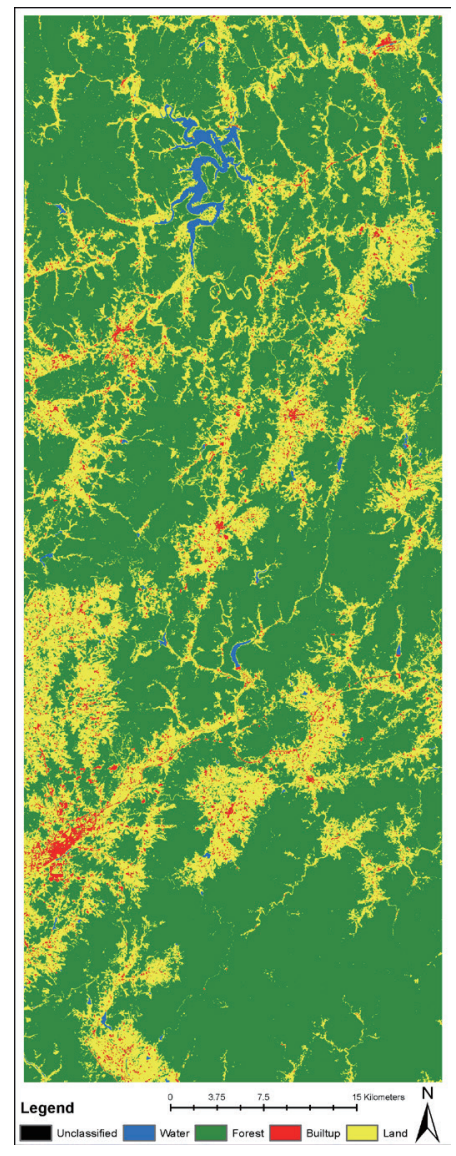

(b)

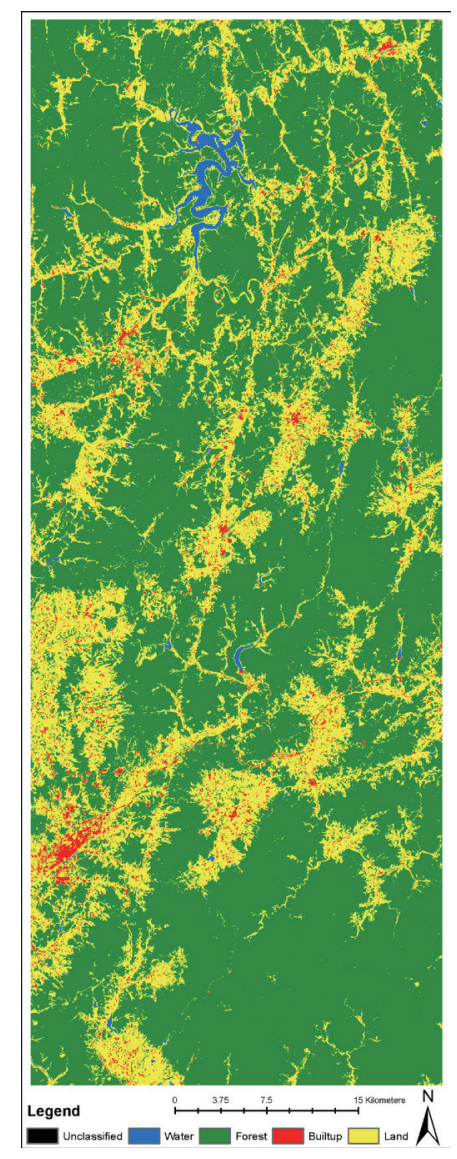

(c)

Fig. 6. (Color online) Results of land cover in combined study area using SVM classification for composite data: (a) original OLI (Comp $)$, (b) OLI bands with NDVI and NDWI (Comp9), and (c) OLI bands with all SIs (Comp 18 ).

Table 5

(Color online) Accuracy assessment statistics of classification algorithms of original OLI band composite (Comp 7 ).

\begin{tabular}{|c|c|c|c|c|c|c|c|c|c|c|c|}
\hline \multirow{2}{*}{ Study area } & \multirow{2}{*}{ Classifier } & \multicolumn{2}{|c|}{ Water } & \multicolumn{2}{|c|}{ Forest } & \multicolumn{2}{|c|}{ Land } & \multicolumn{2}{|c|}{ Built-up } & \multirow{2}{*}{ OA } & \multirow{2}{*}{$\begin{array}{c}\text { Kappa } \\
\text { coefficient }\end{array}$} \\
\hline & & PA & UA & $\mathrm{PA}$ & UA & PA & UA & $\mathrm{PA}$ & UA & & \\
\hline \multirow{5}{*}{ Upper } & MahD & 100 & 94.63 & 100 & 97.77 & 93.05 & 97.39 & 89.15 & 90.55 & 96.95 & 0.949 \\
\hline & ML & 98.45 & 100 & 99.5 & 99.86 & 93.94 & 97.59 & 94.96 & 78.78 & 97.04 & 0.955 \\
\hline & MinD & 100 & 74.19 & 95.01 & 95.63 & 60.78 & 88.34 & 92.25 & 49.38 & 83.29 & 0.757 \\
\hline & PP & 96.65 & 100 & 98.72 & 99.78 & 63.99 & 97.03 & 96.12 & 39.18 & 85.97 & 0.798 \\
\hline & SVM & 99.23 & 100 & 100 & 99.72 & 97.86 & 96.32 & 84.88 & 91.63 & 97.92 & 0.968 \\
\hline \multirow{5}{*}{ Lower } & MahD & 100 & 96.53 & 100 & 99.51 & 91.78 & 97.43 & 87 & 83.65 & 98.95 & 0.954 \\
\hline & ML & 98.56 & 100 & 99.78 & 99.98 & 92.94 & 97.24 & 98 & 75.1 & 99.07 & 0.961 \\
\hline & MinD & 100 & 48.94 & 85.45 & 99.55 & 61.01 & 31.5 & 95 & 49.74 & 83.5 & 0.503 \\
\hline & PP & 97.12 & 100 & 99.6 & 100 & 49.95 & 95.37 & 97.5 & 29.82 & 94.75 & 0.78 \\
\hline & SVM & 100 & 100 & 100 & 99.93 & 97.05 & 97.05 & 86 & 88.66 & 99.43 & 0.976 \\
\hline \multirow{5}{*}{ Combined } & MahD & 100 & 97.59 & 100 & 98.86 & 90.83 & 97.56 & 88.65 & 85.84 & 98.14 & 0.951 \\
\hline & ML & 98.86 & 100 & 99.69 & 99.96 & 92.85 & 97.27 & 96.29 & 75.38 & 98.45 & 0.96 \\
\hline & MinD & 100 & 66.54 & 86.06 & 98.96 & 61.9 & 47.41 & 93.45 & 49.65 & 83.05 & 0.625 \\
\hline & PP & 96.77 & 100 & 99.54 & 99.97 & 55.53 & 95.99 & 96.94 & 33.36 & 92.35 & 0.807 \\
\hline & SVM & 99.81 & 99.62 & 100 & 99.89 & 96.96 & 96.54 & 84.5 & 88.56 & 98.96 & 0.973 \\
\hline
\end{tabular}

All are represented as a percentage $(\%)$. 
Table 6

(Color online) Accuracy assessment statistics of classification algorithms of original OLI bands with NDVI and NDWI band composite (Comp 9$)$.

\begin{tabular}{|c|c|c|c|c|c|c|c|c|c|c|c|}
\hline \multirow{2}{*}{ Study area } & \multirow{2}{*}{ Classifier } & \multicolumn{2}{|c|}{ Water } & \multicolumn{2}{|c|}{ Forest } & \multicolumn{2}{|c|}{ Land } & \multicolumn{2}{|c|}{ Built-up } & \multirow{2}{*}{$\mathrm{OA}$} & \multirow{2}{*}{$\begin{array}{c}\text { Kappa } \\
\text { coefficient }\end{array}$} \\
\hline & & $\mathrm{PA}$ & UA & $\mathrm{PA}$ & UA & $\mathrm{PA}$ & UA & PA & UA & & \\
\hline \multirow{5}{*}{ Upper } & MahD & 98.97 & 100 & 100 & 97.57 & 94.39 & 97.07 & 89.15 & 89.15 & 97.01 & 0.954 \\
\hline & ML & 99.74 & 100 & 99.79 & 99.79 & 91.53 & 98.28 & 94.57 & 72.62 & 96.44 & 0.95 \\
\hline & MinD & 100 & 98.73 & 100 & 92.8 & 74.87 & 97.56 & 91.86 & 58.52 & 90.45 & 0.857 \\
\hline & PP & 96.65 & 100 & 96.87 & 99.78 & 67.91 & 95.61 & 95.74 & 42.08 & 86.51 & 0.805 \\
\hline & SVM & 100 & 100 & 100 & 99.72 & 98.13 & 96.49 & 84.5 & 92.77 & 98.08 & 0.971 \\
\hline \multirow{5}{*}{ Lower } & MahD & 97.12 & 100 & 100 & 99.44 & 90.73 & 97.62 & 91 & 81.61 & 98.89 & 0.952 \\
\hline & ML & 100 & 100 & 99.81 & 99.99 & 92.1 & 97.54 & 97 & 72.39 & 99.02 & 0.958 \\
\hline & MinD & 100 & 99.29 & 100 & 99.43 & 80.72 & 98.33 & 93.5 & 58.44 & 98.01 & 0.914 \\
\hline & PP & 97.12 & 100 & 99.48 & 100 & 59.85 & 99.13 & 97.5 & 35.14 & 95.59 & 0.82 \\
\hline & SVM & 100 & 100 & 100 & 99.93 & 97.15 & 97.05 & 86 & 89.12 & 99.44 & 0.976 \\
\hline \multirow{5}{*}{ Combined } & MahD & 98.29 & 100 & 100 & 98.78 & 90.83 & 96.96 & 89.08 & 85.89 & 98.09 & 0.95 \\
\hline & ML & 99.24 & 100 & 99.77 & 99.97 & 90.44 & 97.7 & 96.29 & 69.34 & 98.14 & 0.952 \\
\hline & MinD & 100 & 98.87 & 100 & 98.4 & 77.02 & 98.03 & 93.01 & 58.04 & 96.1 & 0.898 \\
\hline & PP & 96.58 & 100 & 99.3 & 99.97 & 64.9 & 96.62 & 96.29 & 39.17 & 93.62 & 0.839 \\
\hline & SVM & 100 & 100 & 100 & 99.92 & 97.2 & 96.73 & 85.15 & 88.64 & 99.03 & 0.975 \\
\hline
\end{tabular}

All are represented as a percentage (\%).

Table 7

(Color online) Accuracy assessment statistics of classification algorithms of original OLI bands with all SI composite $\left(\mathrm{Comp}_{18}\right)$.

\begin{tabular}{|c|c|c|c|c|c|c|c|c|c|c|c|}
\hline \multirow{2}{*}{ Study area } & \multirow{2}{*}{ Classifier } & \multicolumn{2}{|c|}{ Water } & \multicolumn{2}{|c|}{ Forest } & \multicolumn{2}{|c|}{ Land } & \multicolumn{2}{|c|}{ Built-up } & \multirow{2}{*}{$\mathrm{OA}$} & \multirow{2}{*}{$\begin{array}{c}\text { Kappa } \\
\text { coefficient }\end{array}$} \\
\hline & & PA & UA & PA & UA & PA & UA & PA & UA & & \\
\hline \multirow{5}{*}{ Upper } & MahD & 100 & 100 & 99.79 & 99.57 & 97.15 & 97.06 & 88.37 & 89.76 & 97.95 & 0.969 \\
\hline & ML & 0 & 0 & 0 & 0 & 0 & 0 & 0 & 0 & 0 & 0 \\
\hline & MinD & 99.23 & 80.88 & 100 & 94.8 & 57.75 & 98.78 & 98.06 & 45.26 & 84.8 & 0.779 \\
\hline & PP & 95.1 & 100 & 95.73 & 99.85 & 79.95 & 95.53 & 91.86 & 55.24 & 89.75 & 0.85 \\
\hline & SVM & 100 & 100 & 100 & 99.65 & 98.13 & 96.49 & 84.5 & 93.16 & 98.08 & 0.971 \\
\hline \multirow{5}{*}{ Lower } & MahD & 98.56 & 100 & 100 & 99.74 & 94.2 & 98.03 & 91 & 83.87 & 99.24 & 0.967 \\
\hline & ML & 0 & 0 & 0 & 0 & 0 & 0 & 0 & 0 & 0 & 0 \\
\hline & MinD & 99.28 & 55.87 & 99.79 & 99.58 & 61.54 & 96.53 & 99 & 47.37 & 96.09 & 0.834 \\
\hline & PP & 97.12 & 100 & 98.24 & 100 & 74.39 & 99.16 & 96.5 & 48.86 & 95.9 & 0.84 \\
\hline & SVM & 100 & 100 & 100 & 99.93 & 97.26 & 97.57 & 88.5 & 89.85 & 99.5 & 0.979 \\
\hline \multirow{5}{*}{ Combined } & MahD & 99.81 & 100 & 99.99 & 99.73 & 95.46 & 97.58 & 89.52 & 85.77 & 98.9 & 0.971 \\
\hline & ML & 0 & 0 & 0 & 0 & 0 & 0 & 0 & 0 & 0 & 0 \\
\hline & MinD & 99.43 & 73.6 & 99.64 & 98.8 & 59.63 & 96.48 & 98.69 & 46.17 & 93.24 & 0.826 \\
\hline & PP & 93.55 & 100 & 98.02 & 99.97 & 75.81 & 92.41 & 94.76 & 49.83 & 94.2 & 0.855 \\
\hline & SVM & 100 & 100 & 100 & 99.9 & 96.96 & 96.45 & 83.84 & 87.87 & 98.95 & 0.973 \\
\hline
\end{tabular}

All are represented as a percentage $(\%)$.

study areas. Similarly, MinD and SVM showed improvement upon adding derivative bands. However, in the case of SVM, adding any of the bands reduced the accuracy.

The classification of the three study areas in ENVI software showed variable results in each case. Most of the classifications improved upon adding derivative bands; some also showed decreases in OA. In a special case, in addition to a great improvement, PP showed an increased number of unclassified pixels. The ML was unable to classify any pixels at all in the composite with all 18 bands. In the case of PP, the unclassified pixels did not fit in any of the decision boundaries in the image data space. Similarly, in the case of the ML, which assumes a normal distribution of pixels of each class and calculates the probability, the threshold seems to be higher than the highest probability calculated for a pixel to fit in any class. 


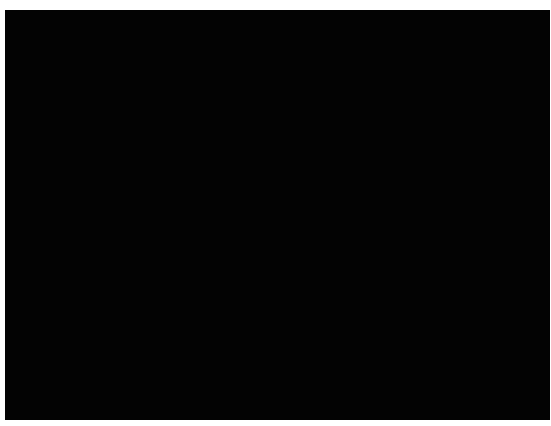

(a)

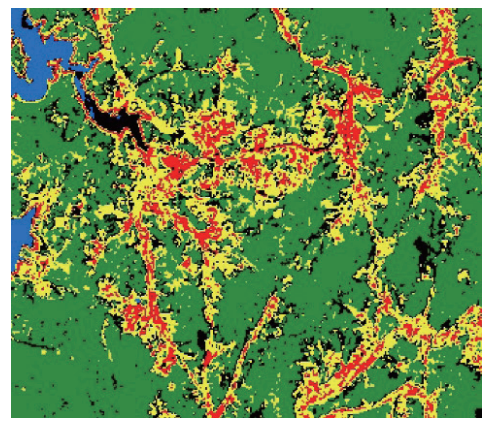

(b)

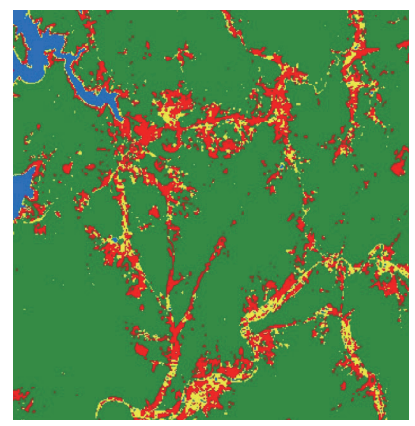

(c)

Fig. 7. (Color online) Common misclassifications in results: (a) completely unclassified (ML in Comp 18 ), (b) some unclassified areas (PP in Comp9), and (c) incorrect classification (MinD in Comp 7 ).

Table 8

(Color online) Score table to show the improvement for three composite images.

\begin{tabular}{|c|c|c|c|c|c|c|c|c|c|c|}
\hline Study area & & Upper & & & Lower & & & Combine & & \\
\hline Classifier & $\begin{array}{l}\text { Comp }_{7} \\
\text { Vs } \\
\text { Comp } 9\end{array}$ & $\begin{array}{c}\text { Comp }_{7} \\
\text { Vs } \\
\text { Comp } 18\end{array}$ & $\begin{array}{c}\text { Comp }_{9} \\
\text { Vs } \\
\text { Comp } 18\end{array}$ & $\begin{array}{c}\text { Comp }_{7} \\
\text { Vs } \\
\text { Comp9 }\end{array}$ & $\begin{array}{c}\text { Comp }_{7} \\
\text { Vs } \\
\text { Comp } 18 \\
\end{array}$ & $\begin{array}{c}\text { Comp }_{9} \\
\text { Vs } \\
\text { Comp } 18\end{array}$ & $\begin{array}{l}\text { Comp }_{7} \\
\text { Vs } \\
\text { Comp } 9\end{array}$ & $\begin{array}{c}\text { Comp }_{7} \\
\text { Vs } \\
\text { Comp } 18 \\
\end{array}$ & $\begin{array}{c}\text { Comp }_{9} \\
\text { Vs } \\
\text { Comp } 18\end{array}$ & Sum \\
\hline MahD & 1 & 1 & 1 & 0 & 1 & 1 & 0 & 1 & 1 & 7 \\
\hline ML & 0 & 0 & 0 & 0 & 0 & 0 & 0 & 0 & 0 & 0 \\
\hline MinD & 1 & 1 & 0 & 1 & 1 & 0 & 1 & 1 & 0 & 6 \\
\hline PP & 1 & 1 & 1 & 1 & 1 & 1 & 1 & 1 & 1 & 9 \\
\hline SVM & 1 & 1 & 0 & 1 & 1 & 1 & 1 & 0 & 0 & 6 \\
\hline Sum & 4 & 4 & 2 & 3 & 4 & 3 & 3 & 3 & 2 & 28 \\
\hline
\end{tabular}

1 indicates improvement, and 0 indicates decrease in accuracy.

Recent studies have shown that SVM performs better than many other algorithms, especially with a small training data set. The main advantage for land cover mapping is the production of more accurate classification. ${ }^{(46-48)}$ In our study also, the performance is better. MahD, which is a direction-sensitive distance classifier that uses statistics for each class and assumes that all class covariances are equal and therefore is a faster method, has also shown better performance and improvement. The increase in the accuracies of MinD and PP needs to be further optimized with the correct threshold value for assigning class to all pixels.

\section{Conclusions}

Land cover mapping has been the most often conducted study in remote sensing thanks to the availability of much data, algorithms, and advanced computing technology. Improving the accuracy of classification has been a challenging task among researchers. In this study, we conducted 45 land cover analyses with five classifiers, in three study areas with original and two derived composites. Among these, 28 cases showed improvements upon stacking of layers with different SIs. PP showed improvement in all cases but at a cost of unclassified pixels. MahD and SVM showed improvement in most cases with higher classification accuracy. ML was unable to classify the composite with all derived bands. In conclusion, layer stacking of the SIs, even two NDVI and NDWI, improved the overall accuracy. Improving the land 
cover classification accuracy is beneficial to authorities for better analyzing the environment. Such an increase in accuracy could be very helpful for environmental and natural resource authorities to provide land cover maps with accurate information quickly, thus enabling a better understanding of the environment. Future works require the selection of a variety of cases with different sensors, different seasons, and individual comparisons of the accuracy of individual or combined SIs.

\section{Acknowledgments}

This research was supported by the Ministry of Land, Infrastructure, and Transport in Korea under the Urban Planning and Architecture (UPA) research support program and was supervised by the Korea Agency for Infrastructure Technology Advancement (KAIA).

Project number: 18DRMS-B147287-01

Project name: Development of customized realistic 3D geospatial information update and utilization technology based on consumer demand

\section{References}

1 A. M. Melesse, Q. Weng, P. S. Thenkabail, and G. B. Senay: Sensors 7 (2007) 3209.

2 R. Manandhar, I. O. Odeh, and T. Ancev: Remote Sens. 1 (2009) 330.

3 B. Lalljee and S. Facknath: Land Use: Reflection on Spatial Informatics Agriculture and Development, M. M. Jha and R. B. Singh, Eds. (Concept Publishing Company, New Delhi, 2008) p. 231.

4 D. Lu and Q. Weng: Int. J. Remote Sens. 28 (2007) 823.

5 B. M. Steele, J. C. Winne, and R. L. Redmond: Remote Sens. Environ. 66 (1998) 192.

6 J. T. Tou and R. C. Gonzalez: Pattern Recognition Principles (Addison-Wesley, Reading, Massachusetts, 1974) p. 377.

7 J. A. Richards and J. Richards: Remote Sensing Digital Image Analysis (Springer, Berlin, 1999).

8 C. Gómez, J. C. White, and M. A. Wulder: ISPRS J. Photogramm. Remote Sens. 116 (2016) 55.

9 T. D. Acharya, I. T. Yang, and D. H. Lee: Appl. Sci. 6 (2016) 371.

10 J. J. Walker, K. M. de Beurs, R. H. Wynne, and F. Gao: Remote Sens. Environ. 117 (2012) 381.

11 J. R. Otukei and T. Blaschke: Int. J. Appl. Earth Obs. Geoinf. 12, Supplement 1 (2010) S27.

12 C. Castañeda and D. Ducrot: J. Environ. Manage. 90 (2009) 2270.

13 A. Huete, K. Didan, T. Miura, E. P. Rodriguez, X. Gao, and L. G. Ferreira: Remote Sens. Environ. 83 (2002) 195.

14 A. Bannari, D. Morin, F. Bonn, and A. R. Huete: Remote Sens. Rev. 13 (1995) 95.

15 R. D. Jackson and A. R. Huete: Prev. Vet. Med. 11 (1991) 185.

16 C. Li, P. Gong, J. Wang, C. Yuan, T. Hu, Q. Wang, L. Yu, N. Clinton, M. Li, J. Guo, D. Feng, C. Huang, Z. Zhan, X. Wang, B. Xu, Y. Nie, and K. Hackman: Int. J. Remote Sens. 37 (2016) 4623.

17 J. Liu, J. Heiskanen, E. Aynekulu, E. E. Maeda, and P. K. Pellikka: Remote Sens. 8 (2016) 365.

18 F. Yuan, K. E. Sawaya, B. C. Loeffelholz, and M. E. Bauer: Remote Sens. Environ. 98 (2005) 317.

19 J. Vogelmann, T. Sohl, P. Campbell, and D. Shaw: Environ. Monit. Assess. 51 (1998) 415.

20 R. S. Defries and J. R. G. Townshend: Int. J. Remote Sens. 15 (1994) 3567.

21 U. S. Geological Survey: Landsat 8: U.S. Geological Survey Fact Sheet 2013-3060 (2013).

22 G. Chander, B. L. Markham, and D. L. Helder: Remote Sens. Environ. 113 (2009) 893.

23 Y. Ke, J. Im, J. Lee, H. Gong, and Y. Ryu: Remote Sens. Environ. 164 (2015) 298.

24 P. Li, L. Jiang, and Z. Feng: Remote Sens. 6 (2013) 310.

25 D. P. Roy, V. Kovalskyy, H. K. Zhang, E. F. Vermote, L. Yan, S. S. Kumar, and A. Egorov: Remote Sens. Environ. 185 (2016) 57.

26 Y. Zhou, X. Xiao, Y. Qin, J. Dong, G. Zhang, W. Kou, C. Jin, J. Wang, and X. Li: Int. J. Appl. Earth Obs. Geoinf. 46 (2016) 1.

27 J. S. Rawat and M. Kumar: Egypt. J. Remote Sens. Space Sci. 18 (2015) 77. 
B. C. Ko, H. H. Kim, and J. Y. Nam: Sensors 15 (2015) 13763.

T. D. Acharya and I. T. Yang: IJIEASR 4 (2015) 4.

30 U. S. Geological Survey: http://landsat.usgs.gov/landsat8.php (accessed July 2016).

31 A. R. Huete, H. Q. Liu, K. Batchily, and W. van Leeuwen: Remote Sens. Environ. 59 (1997) 440.

32 Z. Jiang, A. R. Huete, K. Didan, and T. Miura: Remote Sens. Environ. 112 (2008) 3833.

33 X. Xiao, S. Boles, S. Frolking, W. Salas, B. Moore, C. Li, L. He, and R. Zhao: Int. J. Remote Sens. 23 (2002) 3009.

34 H. Xu: Int. J. Remote Sens. 27 (2006) 3025.

35 J. M. Chen: Can. J. Remote Sens. 22 (1996) 229.

36 Y. Zha, J. Gao, and S. Ni: Int. J. Remote Sens. 24 (2003) 583.

37 J. W. Rouse, R. H. Haas, J. A. Schell, and D. W. Deering: Third Earth Resources Technology Satellite-1 Symp. (NASA SP-351) (1973) 309.

38 B. Gao: Remote Sens. Environ. 58 (1996) 257.

39 A. R. Huete: Remote Sens. Environ. 25 (1988) 295.

40 G. S. Birth and G. R. McVey: Agron. J. 60 (1968) 640.

41 M. H. A. Baig, L. Zhang, T. Shuai, and Q. Tong: Remote Sens. Lett. 5 (2014) 423.

42 W. Li, Z. Du, F. Ling, D. Zhou, H. Wang, Y. Gui, B. Sun, and X. Zhang: Remote Sens. 5 (2013) 5530.

43 M. Hall, E. Frank, G. Holmes, B. Pfahringer, P. Reutemann, and I. H. Witten: SIGKDD Explor. Newsl. 11 (2009) 10.

44 Harris Geospatial Solutions: http://www.harrisgeospatial.com/docs/routines-136.html (accessed August 2017).

45 S. Yousefi, H. R. Pourghasemi, J. Hooke, O. Navratil, and A. Kidová: Geomorphology 271 (2016) 55.

46 S. Yousefi, R. Khatami, G. Mountrakis, S. Mirzaee, H. R. Pourghasemi, and M. Tazeh: Environ. Monit. Assess. 187 (2015) 1.

47 A. Halder, A. Ghosh, and S. Ghosh: Appl. Soft Comput. 11 (2011) 5770.

48 G. Mountrakis, J. Im, and C. Ogole: ISPRS J. Photogramm. Remote Sens. 66 (2011) 247.

\section{About the Authors}

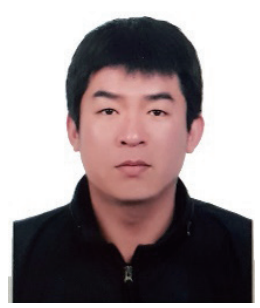

Jae Kang Lee received his $\mathrm{Ph} . \mathrm{D}$. in engineering surveying from the University of Nottingham, United Kingdom, in 2016. Currently, he is working in LX Korea Land and Geospatial InformatiX Corporation as principal researcher. His research interests are in geospatial data processing and analysis, and positioning-based facility management and inspection.

(jaekang.lee@1x.or.kr)

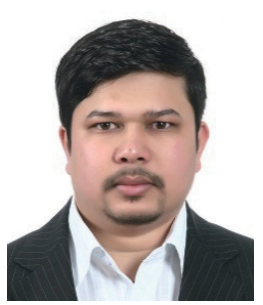

Tri Dev Acharya received his B.E. in geomatics from Kathmandu University, Nepal, in 2011, and his Combined M.S. and Ph.D. degree from Kangwon National University, Korea, in 2018. He is now a postdoc researcher at Kangwon National University, Korea. His research interests are in geospatial data preparation, modelling, and simulation of land cover, surface water, and natural hazards using various machine-learning algorithms.

(tridevacharya@kangwon.ac.kr)

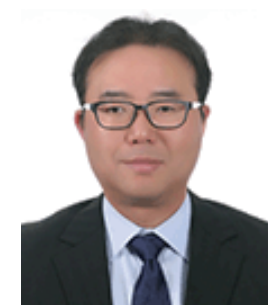

Dong Ha Lee received his B.E., M.S., and Ph.D. degrees from Sungkyunkwan University, Korea, in 2000, 2003, and 2008, respectively. Since 2015, he has been an assistant professor at Kangwon National University, Korea. His research interests are in geodesy, surveying, geospatial information, and natural hazard analysis. (geodesy@kangwon.ac.kr) 